GORDON, JOHN S. (1948), The Laryngoscope, 58, 1265.

GRAHAM, J. D. P. (1947), F. Pharmacol. and Exp. Therap., 91, 103.

HALPERN, B. N. (1947), fourn. Allergy, 18, 263.

HERXHEIMER, H. (1948), Lancet, i, 667.

HERXHEIMER, H. (1949), Brit. Med. F., 2, 901 .

HOFBAUER, J. (1926), f. Obstet. and Gynaec., 12, 159.

HUNTER, R. B., and HILL, A. G. S. (1947), Brit. Med. F., 2, 283.

HUNTER, R. B., and DUNLOP, D. M. (1948), Quart. F. Med., I7, 271.

KAPELLER-ADLER, R. (194I), F. Obstet. Gynaec'Brit. Emp., 48, 155.

KAPELLER-ADLER, R. (1943), Ibid., 50, 177.

KLEIN, S. P. (1948), Arch. Int. Med., 81, 316.

KNOX, L. (1949), South African Med. F., 23, 155.

LEAVI'TT, M. D., and GASTINEAU, C. F. (1947), Arch. Int. Med., 80, 271.

LEVIN, S. J. (1946), f. Allergy, 17, 145.

LEVIN, S. J. (1949), F. Paediat., 34, 616.

LEWIS, T. (1,927), 'Blood vessels of the human skin and their responses,' London, Shaw \& Sons.

LOFSTROM, J. E., and NURNBERGER, C. E. (1946), Ann. Y. Roentgenol. and Rad. Therap., 56, 211.
LOVELESS, M. H., and BROWN, H. (1947), New Eng. Med. f., 237, 501 .

MCEVEDY, M. B. (1949), Lancet, i, 825.

McGAVACK, T. H., et al. (1948), Amer. Y. Med. Sci., 216, 437.

MCGAVACK, T. H. (I949), Annals Allergy, 7, 232.

MAINS, M. P. (1949), Radiology, 52, 579.

POULSEN, H. (1949), Nordisk Medicin, 41, 627.

ROSENBERG, M. H., and BLUMENTHAL, L. S. (1949), Amer. f. Med. Sci., $216,158$.

RYAN, G. M. S., and WOOD, J. S. (1949), Lancet, i, 258.

SCHILD, H. O. (1936), F. Physiol., 86, 51.

SCHILD, H. O. (1949), Proc. Roy. Soc. Med., 42, 623.

SERAFINI, U. (1948), f. Allergy, 19, 256.

SOUTHWELL, N. (1949), Practitioner, 162, 148.

STEINBERG, L., and GOTTESMAN, J. (1948), Ann. Allergy, 6,569 .

STRICKLAND, B. A., and HAHN, G. L. (1949), Science, 109, 359 WALDBOTT, G. L., and YOUNG, M. I. (1948), $\mathcal{Y}$. Allergy, 19, 313.

WOOLDRIDGE, W. D., and JOSEPH, H. L. (1948), f. Invest. Derm., II, 95.

ZELLEN, M. (1949), Ann. Allergy, 7, 103.

ZOLOV, B. (1949), Ann. Allergy, 7, 254.

\title{
THE LEGAL DUTY OF THE DOCTOR AS REGARDS SKILL AND CARE
}

\section{By A BARRISTER}

Let us suppose that A goes to B and asks B to give him medical advice and attention. $B$ is not a doctor and tells him so, but A says that he has every confidence in B's common sense and that is enough for him. If $B$ then proceeds to treat $A$ and does his best but, owing to his lack of the necessary skill and knowledge, A suffers some injury from the treatment, A will not have any remedy at law against $B$. He committed himself to $B$ at his own risk and (to quote a legal phrase) $B$ did not warrant his skill. In short, the beginning of a doctor's liability to his patient lies in the fact that the doctor warrants his skill and holds himself out as having the necessary skill and knowledge reasonably required for the discharge of the duties of his profession.

What kind of a liability is this? Is it a liability in contract or in tort? It is not necessary for me to deal with this distinction at any length. If a motorist carelessly knocks down a pedestrian and injures him, he is liable in damages, although he has no contract with the pedestrian and so committed no breach of contract by his careless driving. $\mathrm{He}$ is liable in tort. On the other hand, if I order (say) potatoes of a certain quality and the tradesman accepts the order and then sends potatoes of an inferior quality, I have an action against him for breach of contract and I could not sue him unless I had a contract with him. In many instances a patient, whose doctor has failed to use proper care and has thereby caused some detriment to him, can sue the doctor in contract as well as tort. In some instances he cannot sue in contract but only in tort, e.g. suppose the carelessness occurs in the treatment of a patient who is brought into a hospital in an unconscious condition and occurs whilst he is still unsonscious, the idea of a contract between the patient and the doctor would hardly seem appropriate to the cirsumstances. But I shall not for present purpòses trouble about this distinction in the cause of action, as lawyers call it. The damages recoverable would probably be the same, whether the patient sued in contract or in tort or in both. I shall speak of the doctor's duty and treat the word ' duty' as covering the whole of the doctor's responsibility in law, whatever be the legal conception from which it is derived, and I shall speak of a breach of that duty 
as negligence, although the words 'duty' and 'negligence' would prima facie, suggest to a lawyer a cause of action in tort and not also a cause of action in contract.

The duty of a doctor is to use proper skill, knowledge and care not falling below the standard of the ordinary good doctor in the branch of the profession to which he belongs and to use such skill, knowledge and care in the treatment of the patient throughout, in examination and in diagnosis, in the prescribing of remedies, in the performance of an operation, in post-operative care, and in considering whether the duty has been discharged all the circumstances must be taken into account. It may be said that this statement is vague and uncertain, but the answer to that criticism is that the subject-matter does not permit of a precise definition. The justice of that answer may be illustrated in many ways. For the same stage in the development of the same disease I presume that it might be unreasonable to prescribe for one patient the treatment which might reasonably be prescribed for another, for the reason that differences of physical condition or even of temperament between them would make it wrong to treat them both in the same way. On the same principle it might be wrong to do a certain operation without certain preliminary examination or without the use of a certain technique in a large and up-to-date hospital, where all that was needed, whether in mechanical equipment or in human aid, for such examination and technique was ready and waiting. But it might be quite reasonable and right to take the risk of doing the operation without the one or the other in some remote spot, whether neither was possible or procurable, if the condition of the patient upon such examination as was practicable appeared to require the operation. I remember a story of an eminent surgeon, who was spending his holidays in an out-of-the-way part of the country. He was summoned suddenly to a remote farm in a wild moorland district and had to operate immediately at night without the benefit of many things which would have been ready to hand in a hospital or well-equipped nursing home, and the only available illuminants were lamps and candles. Everything, in fact, went well. But, if an operation has to be performed in such difficult conditions, the law should and will have regard to them in the event of an allegation of negligence. In such circumstances a surgeon might without negligence do something which he would not have done in performing the same operation under more normal conditions.

I take the following words from a judgment in the Court of Appeal in a case against a surgeon. 'It is desirable to recall the well-established legal measure of a professional man's duty. If he professes an art he must be reasonably skilled in it. . . . He must also be careful, but the standard of care which the law requires is not insurance against accidental slips. It is such a degree of care as a normally skilful member of the profession may reasonably be expected to exercise in the actual circumstances of the case in question. It is not every slip or mistake which imports negligence and, in applying the duty of care to the case of a surgeon, it is peculiarly necessary to have regard to the different kinds of circumstances that may present themselves for urgent attention.'

The above standard aoes not require every doctor to manifest the highest degree of skill and knowledge. Doctors, like other professional men, presumably vary in these qualities. It would, for example, be unreasonable to expect the general practitioner to deal with a problem which suddenly confronts him, as if he were the equal in skill and knowledge of the specialist who may have devoted a lifetime to the study of the particular disease. On the other hand, the doctor must not fall below the above standard, which may be said to call upon doctors as a whole for as much knowledge and skill as can fairly be required from every individual doctor as a minimum, when everything is taken into account. In applying the standard the law treats a doctor according to what he professes. The law will require from a specialist in that field of medicine in which he professes to be a specialist a higher degree of skill and knowledge than it' would require in the same field from a competent general practitioner who makes no such profession. The court will assess the appropriate standard, not on the basis of some general statement which is supposed to be applicable to all cases, but upon the evidence of medical witnesses who are called as experts and who give their evidence in relation to the facts of the case which is before the court.

I quote some words from another judgment in the Court of Appeal in the same surgical case: 'I would not for a moment attempt to define in vacuo the extent of a surgeon's duty in an operation beyond saying that he must use reasonable care, nor can I imagine anything more disastrous to the community than to leave it to a jury or a judge, if sitting alone, to lay down what it is proper to do in any particular case without the guidance of witnesses who are qualified to speak on the subject.' 'The same learned Lord Justice in one of the next lines of the same judgment speaks of the surgeon's duty as regards the removal of swabs, and he says that the surgeon must use that degree of care which is reasonable in the circumstances, and then he adds, '. . . and that must depend on the evidence.' 
The branch of the medical profession from which doctors are called as expert witnesses to give this evidence will vary in relation to the kind of case which is under consideration. If the claim arose from an operation performed by a surgeon, for example, one would expect evidence from surgeons. But this observation cannot be rigidly applied, e.g. so as to exclude the evidence of a specialist if the case involved a general practitioner and not a specialist. I should like to use a line or two of the space available for this article by saying that I still have a vivid recollection of the powers of lucid exposition displayed by a young surgeon, whom I heard years ago giving evidence in a county court.

There is, of course, a distinction between not having the necessary skill or knowledge and failing to use it properly although you possess it, and defective treatment of a patient might result from one or other of these two causes. It would not matter much to the patient whether his plight was due to the one cause or to the other, and the distinction may not be of much forensic importance, as the legal issue tends to present itself in the form: Did the defendant do or fail to do something which in the circumstances he would not have done or failed to do, if he had come up to the standard which the law imposes on him? This is the practical point on which success or failure will depend in court.

It is not difficult to think of other legal problems which may arise from the application of the standard of care, skill and knowledge which the law requires of a doctor. Let me give one or two examples. First, is a doctor bound to be absolutely up to date in his knowledge or his methods? The answer to this question cannot be no, but neither can it be a simple yes. It would have to be yes subject to a qualification which is familiar in such problems, 'but it must be a question of degree.' Thus, for example, if the new discovery was a new drug, it might as yet have been employed only in cases under strict observation and control in hospitals or nursing homes, and so might not yet be ripe for general use. On the other hand, if all the experimental stages had been successfully accomplished and the drug was ready for general use, the question would be whether the doctor ought to know about it. The answer would be easier if the defendant was a specialist and the drug related to his special field of practice, than if he were a general practitioner. The case for the plaintiff would probably not be easy to prove. Such propositions as these, viz. (if the patient had died), " $\mathrm{He}$ would have recovered, if the drug had been prescribed for him,' or (if the patient were the plaintiff) 'I should have made a quicker or a more complete recovery if you had prescribed the drug for me;' would appear, at least to a lawyer, to be matters susceptible of much controversy even amongst experts.

Another example is provided by the question of calling in a specialist. Let me assume that the case is surgical. When ought the general practitioner to call in a surgeon? The only answer that can be given is, that he should do so when competent general practitioners would conceive it to be their duty to do so. No hard and fast line can be drawn and no precise definition can be framed which will always supply a ready answer to the question. What will the result be in law if he himself performs the operation in a case where, on the application of the above test, he ought to have called in a specialist to perform it? He ought not to have undertaken the operation except in an emergency when no surgeon was available or unless he pointed out to his patient that the operation called for the ability of a specialist, that is of a surgeon, but the patient insisted upon his performing the operation himself. I think that the English law in such circumstances is to that effect. If he undertakes the operation when those conditions are not fulfilled, he fails to exercise due care towards his patient and, supposing that the patient can prove that he suffered some injury which he would not have suffered it the operation had been performed by a surgica specialist, the patient will be entitled to recover damages from him.

Let me take another example which is suggested by a case from the Dominions. In assessing the right standard of (say) surgical practice, how far afield is a court to look? I believe that surgeons in one country have regard to experiments and new methods of surgery in other countries. Should the court which is trying a case in country A have regard to the standards of surgery not only in country A but in country B also? The answer to that question is probably no. On the other hand, the court would certainly be averse to a further distinction which would result in the setting up of one standard of surgery for one part and another standard for another part of the same country. The answer to these and similar questions will depend ultimately on the test of reasonableness in the light of all the circumstances.

It is probable that legal decisions of disputes between doctor and patient are chiefly associated in the minds of most laymen with one or two classes of cases, and one of them would be cases in which a swab has been left inside the patient's body. I doubt whether the ordinary public realize how easily a surgeon or his assistants may fail to see a swab in a wound. The ordinary uninstructed ' man in the street,' as the current phrase goes, 
or ' man on the Clapham omnibus,' as Lord Bowen described the same type of person, can hardly be blamed perhaps for saying that, if a swab is left in the patient at the end of the operation, someone must have been careless, and for looking first in the direction of the surgeon in the search for the culprit. Lawyers who deal with such cases realize, of course, that the matter is not as simple as thit statement would assume. They appreciate that the surgeon, in the interests of the patient, must concentrate his attention on many matters which in urgent and vital importance should be ranked well above the memorizing of the number of swabs used in the operation. Therefore, if he fails to remove a swab before the wound is closed and injury results from the presence of that swab, these two facts by themselves may yet not be enough to constitute a conclusive case against the surgeon. The question whether he has been negligent or not must be decided on a view of all the facts of the particular case. This is a principle of great importance.

One or two points arising out of swab cases should perhaps be considered a little more fully. First, I understand that it is common to arrange that the counting of the swabs which are used during the operation and the counting of the swabs which are taken out shall be entrusted to the sister in charge of the operating theatre or some other responsible person, and that the surgeon shall leave the counting to her and proceed to close the wound when she has informed him that all the swabs which were put in have been duly counted out again. Is this sufficient? I assume that the system of checking the swabs put in and taken out is so thoroughly and effectively organized that it will work perfectly, subject only to the inescapable contingency of human error. That being so, the question has arisen whether the surgeon has a duty to do something more than inquire of the sister whether she is satisfied that all the swabs have been removed, viz. whether he should not only make the inquiry of the sister but should make a search for the swabs himself by some appropriate method, assuming that such a search is practicable, either before or after he makes the inquiry.

This question must depend on expert evidence. I shall venture to offer one or two illustrations. Let me suppose that after a major operation, when several swabs were used, the surgeon was told by the experienced sister in charge of the counting of the swabs that all the swabs were out of the body; one swab, however, was still in the body and remained there; as a result the patient suffered some injury, had to undergo another operation, and now sues the surgeon who did the first operation. As regards the expert evidence, let me suppose that evidence is given by experts called on behalf of the surgeon and is accepted by the court, that with a view to the effectiveness of surgery in such major operations it is both desirable and usual that the checking of the swabs should be left by the surgeon entirely to an experienced sister and that he should act on her assurance that all the swabs have been removed. Let me suppose, also, that the experts gave evidence that in the particular case before the court no examinations for swabs by the surgeon could properly or safely have been made, as it must have been made by touch as well as by sight and, in view of the condition of the patient, could not have been made without serious increase of risk to him. In those circumstances one would expect the judgment to be for the surgeon. On the other hand, if the view of the experts was that in the particular case before the court such an examination could have been made with little or no increase of risk to the patient and might have led to the discovery of the swab, one would expect that it would at once become difficult to persuade the Court that there was not lack of due care in the omission of the examination. Analogous cases approaching one or the other of the two above alternatives will no doubt occur readily to those with surgical experience.

The second point relates to the effect as a matter of evidence of the bare proof of the two facts, that a swab was left in the body and that in consequence of its being left there the plaintiff suffered injury. Upon proof of these two facts does the burden of proof then shift to the defendant, so that, unless the defendant can show that the swab was not left there because of any failure on his part to exercise proper skill and care, he will fail and the plaintiff will be entitled to judgment against him.

This problem may be stated in a slightly different form. On the above suppositions must the plaintiff then, in order to succeed, go on to prove that the defendant has been guilty of some lack of skill or care, or will the plaintiff be then entitled to judgment unless the defendant proves that he has exercised due skill or care? In answer, one school of thought would say, 'In that state of facts the surgeon is called upon to show that he did in fact exercise due skill and care,' whilst another would say, 'A judge, unless instructed by expert evidence, cannot decide whether in that state of facts the surgeon has or has not failed to exercise due care.' The question has not yet been determined and may in practice prove to be academic, because the issue is hardly likely to arise in court without such expert evidence being provided for the court by one or both of the parties. 
I ought perhaps to add one further observation about the litigation of such claims. In a recent case the claim was brought against the surgeon and the sister who had been responsible for the counting of the swabs. I suppose that this was done on the basis that the combined duties of the two of them together covered the whole field of activity, within which any negligence connected with the non-extraction of the swab must have occurred. A similar joinder of defendants would be likely to be made in any similar case. If more than two persons may be involved in the negligence, more than two may be brought in as defendants. This is, after all, a natural procedure, if it is certain or almost certain that, assuming negligence to have occurred, one or more of (say) three persons are guilty of the negligence, but it is still uncertain to which the blame is to be attributed, and only the investigation of the facts at the trial will settle the matter. The plaintiff will have good reason for being cautious about joining as defendants persons against whom he is not likely to succeed, inasmuch as he may have to pay their costs. The questions of the assessment of the damages which a successful plaintiff is entitled to recover, and of the apportionment of damages if the plaintiff succeeds against more than one defendant, do not fall within the scope of this article.

\title{
INTUSSUSCEPTION IN CHILDREN \\ Its Diagnosis and Treatment
}

\author{
By Dr. Jens Munck Nordentoft \\ Physician in Charge of the Department of Radiology, Aalborg County Hospital, Denmark
}

The treatment of intussusception in children by conservative measures (encmata or manipulation) is very old. During the earlier years of this century, as the safety of operative treatment increased, it was almost abandoned. Here and there, however, it still had advocates. The great advantage of conservative treatment is obvious; laparotomy is avoided. It is, however, a blind measure and its greatest danger was the fact that its success or failure was never immediately known. In a large number of cases it was not discovered that the reduction had been incomplete until hours or days had passed. Precious time was thus wasted, the risks of laparotomy had increased and a high mortality resulted.

To-day the non-operative treatment of intussusception in children in its modern form with the barium enema under fluoroscopic control is almost without danger, provided always that it is administered by an experienced radiologist. With $\mathrm{X}$-rays the diagnosis can be confirmed at once, the topical diagnosis can often be exact, and one can with certainty know when reduction is complete. It is, however, essential that the radiologist in charge shall be a man of skill and experience in interpreting the radiological findings.

\section{The History of the Barium Enema Method}

The barium reduction method has especially gained ground in those countries where the simple enema and manipulation methods had never been given up, and where their considerable advantages were appreciated. The fact that the barium enema method has not been accepted in AngloSaxon countries is no doubt due to the fact that the old methods had there been quite abandoned before the barium method was introduced in 1927 . Certain series of good results of operative treatment from surgical departments of children's hospitals certainly contributed to this, as probably also did unwise and unskilled adherents of the older conservative school.

In the writings of last century the use of a column of water 4 to $6 \mathrm{~m}$. ( 13 to $20 \mathrm{ft}$.) is recommended, to be applied by "laying the child in the hallway and raising the funnel by mounting the stairs.' Mortimer tried to find out how great a pressure the normal colon can withstand 